\title{
Hypertriglyceridemia and Lower LDL Cholesterol Concentration in Relation to Apolipoprotein E Phenotypes in Myotonic Dystrophy
}

\author{
Sital Moorjani, Daniel Gaudet, Claude Laberge, Marie Christine Thibault, \\ Jean Mathieu, Jean Morissette, \\ Paul J. Lupien, Daniel Brun and Claude Gagné
}

\begin{abstract}
Plasma lipid, lipoprotein levels and apolipoprotein apo E phenotypes were determined in 70 patients with myotonic dystrophy (MyD) and 81 controls. Marked differences were noticed in the apo E phenotype frequencies between the two groups. Plasma triglycerides and VLDL cholesterol were higher in MyD than controls, but only the latter was related to differences in the apo E phenotypes between two groups. Accordingly, the ratio of VLDL cholesterol/plasma triglycerides was increased significantly in MyD, suggesting accumulation of intermediary density particles due to lower affinity of E2 containing lipoproteins for lipoprotein cell receptors. The LDL cholesterol concentration was lower in $\mathrm{MyD}$ than controls and was related to differences in the apo $\mathrm{E}$ phenotype frequencies between the two groups. These results indicate increased removal of LDL particles in the apo E2 phenotypes, perhaps due to upregulation of $\operatorname{LDL}(B, E)$ receptor activity. Plasma cholesterol and HDL cholesterol concentrations were similar in both groups. Another feature of the study was lower levels of plasma cholesterol, triglycerides, VLDL and LDL cholesterol in the homozygous E4:E4 phenotype. These results suggest increased clearance rate of both VLDL and LDL particles and support the concept that apo E4-containing lipoproteins have higher in vivo affinity for ape $\mathrm{E}$ and/or $\mathrm{B}, \mathrm{E}$ receptors.

RÉSUMÉ: Phénotypes de l'apolipoprotéine E dans l'hypercholestérolêmie associée à la diminution des niveaux de cholestérol-LDL dans la dystrophie myotonique Le dosage des lipides, des lipoprotéines plasmatiques, de même que les phénotypes de l'apolipoprotéine E (apo E) ont été effectués chez 70 patients souffrant de la dystrophie myotonique (DM) de même que sur 81 sujets contrôles. Des différences significatives ont été observées dans les fréquences des phénotypes d'apo $\mathrm{E}$ entre les deux groupes. Les niveaux de triglycérides et cholestérol-VLDL plasmatiques se sont avérés plus élevés chez les patients DM, comparativement aux contrôles, alors que seulement le cholestérol-VLDL était associé aux différences des les fréquences de phénotypes d'apo $E$ entre les deux groupes. Parallèlement, le rapport cholestérol-VLDL/triglycérides plasmatiques était significativement augmenté chez les patients DM, suggérant l'accumulation des lipoprotéines de densité intermédiaire. Ces résultats peuvent s'expliquer par la faible affinité de l'apo E2 pour les récepteurs cellulaires. Chez les DM, une diminution du cholestérol-LDL était associée aux différences dans les fréquences de phénotypes d'apo $E$ entre les deux groupes. Ces résultats indiquent une augmentation de la clairance des LDL dans les phénotypes impliquant l'apo E2, phénomène découlant de la "up regulation" de l'activité des récepteurs (B, E) des LDL. Les taux plasmatiques du cholestérol et du cholestérol-HDL étaient semblables dans les deux groupes. Une autre observation de cette étude a été la diminution des taux plasmatiques de cholestérol total, triglycérides et cholestérol des fractions VLDL et LDL chez les homozygotes d'apo E4 (E4:E4). Ces résultats indiquent une clairance accrue des VLDL et LDL et appuient l'hypothèse d'une plus grande affinité in vivo pour les récepteurs de l'apo $\mathrm{E}$ et/ou les récepteurs $\mathrm{B}, \mathrm{E}$ des $\mathrm{LDL}$.
\end{abstract}

Can. J. Neurol. Sci. $1989 ; 16: 129-133$

Recently, we described linkage between the loci for MyD and apolipoprotein $\mathrm{E}$ (apo E) in family studies. ${ }^{1}$ It is known that the structural gene locus for apo $E$ exhibits polymorphism. The alleles, designated $\varepsilon 2, \varepsilon 3$, and $\varepsilon 4$, code for the three major iso- proteins, E2, E3 and E4, respectively, and determine six different apo $E$ phenotypes. ${ }^{2}$ Our linkage studies also revealed higher frequencies of the rarer isoforms of apo $E$ in families with $M y D$ as compared to apo $E$ isoform frequency distribution in various

From the Lipid Research Unit, Le Centre Hospitalier de l'Université Laval (S.M., P.J.L., D.B., C.G.); Human Genetics, Le Centre Hospitalier de l'Université Laval (D.G., C.L., M.C.T., J.M.); Muscular Dystrophy Clinic, Hôpital de Chicoutimi (J.M.)

Reprint requests to: Sital Moorjani, Lipid Research Unit, Le Centre Hospitalier de l'Université Laval, 2705 Boulevard Laurier, Sainte-Foy, Québec, Canada GIV 4G2 
Caucasian populations. ${ }^{3}$ Apo $E$ is one of the protein constituents of plasma lipoprotein particles. It mediates lipoprotein catabolism by binding to high affinity cell surface receptors ${ }^{4}$ and thus contributes considerably in determining the plasma levels of cholesterol, triglycerides and various lipoprotein fractions.

Reports on circulating lipids in MyD are fragmentary and also inconsistent, showing elevation of both plasma cholesterol and triglycerides ${ }^{5}$ or no increase in either. ${ }^{6}$ Due to the variable effects of apo $E$ alleles on plasma lipids and lipoproteins in population studies ${ }^{3}$ and also due to the higher frequency of rarer apo $E$ isoforms in families with MyD, we studied the effects of apo $\mathrm{E}$ phenotypes on plasma lipids and lipoprotein concentrations to further our understanding of these relationships.

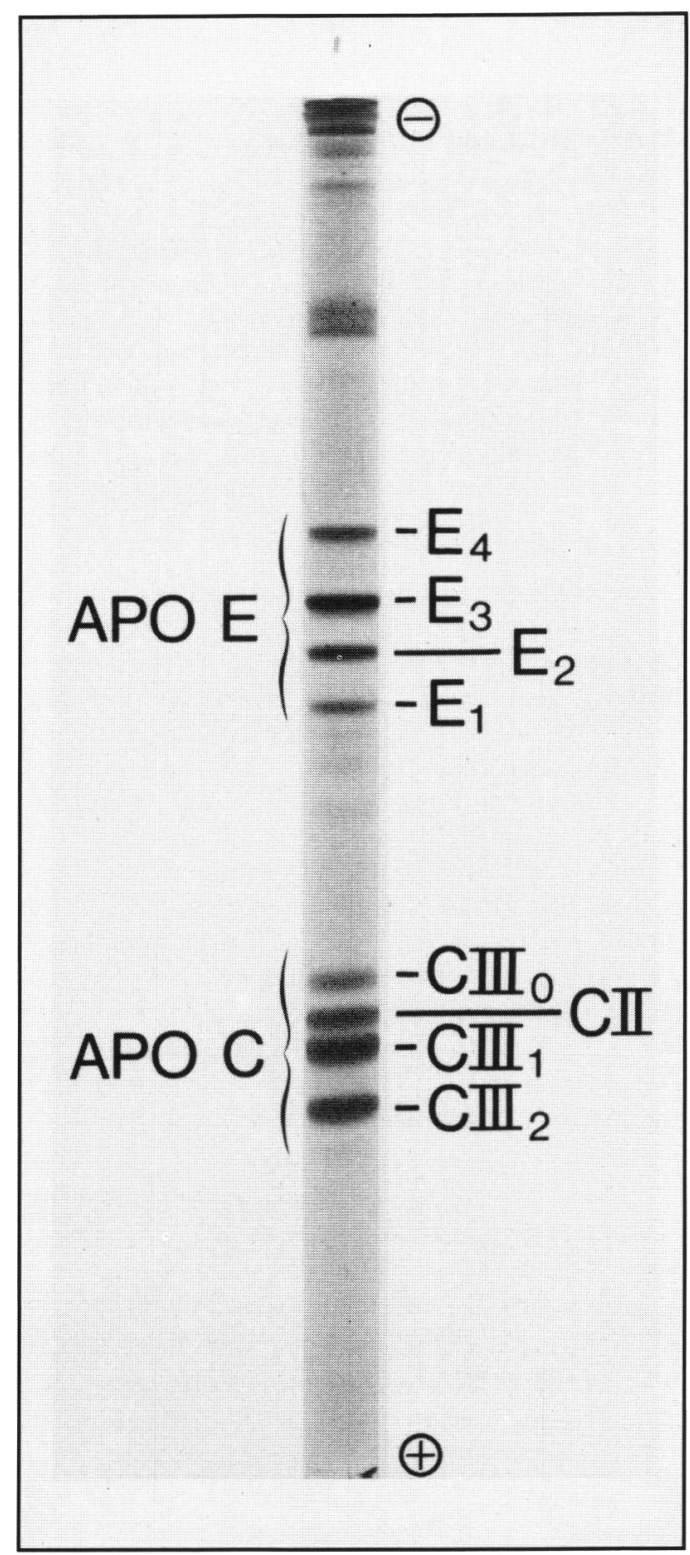

Figure I - A typical banding pattern of apo-VLDL in analytical isoelectric focusing electropheresis on polyacrylamide gels.

\section{Materials AND MeThods}

\section{Subjects}

The data in this study are derived from 39 families with MyD. A total of 151 individuals with an average age of 37 years and varying in age from 8 to 83 years were sampled. Blood samples were obtained and the plasma was separated and stored at $4^{\circ} \mathrm{C}$ as described previously. $7^{7} \mathrm{MyD}$ was diagnosed in 70 patients ${ }^{8}$ and the remaining 81 unaffected subjects (spouses and first degree relatives) were included in the study as controls. Males $(n=35)$ and females $(n=35)$ were equally represented in the MyD group and had similar average age of 36 years (range, 8-81) and 35 years (range, 14-83), respectively. The control group was composed of 31 males and 50 females with average age of 35 years (range, 18-63) and 42 years (range, 10-79), respectively.

\section{Laboratory methods}

Plasma cholesterol, triglycerides and lipoprotein cholesterol were determined as previously described. ${ }^{7}$ The apo E phenotypes were determined as follows: the isolated VLDL fraction ${ }^{9}$ was delipidated with acetone: ethanol $(1: 1, \mathrm{v} / \mathrm{v})$ followed by diethyl ether at $-20^{\circ} \mathrm{C}$. The colorless precipitated protein was dried under $\mathrm{N}_{2}$ at room temperature and stored at $-20^{\circ} \mathrm{C}$. Apo VLDL was solubilized in $10 \mathrm{mM}$ Tris- $\mathrm{HCl}, \mathrm{pH} 8.2$, containing $8 \mathrm{M}$ urea and $30 \mathrm{mM}$ dithiothreitol, just before electrophoresis. The apo $E$ isoproteins were separated by isoelectric focusing electrophoroesis in $7.5 \%$ polyacrylamide gels containing $8 \mathrm{M}$ urea and $2.0 \%$ ampholines (LKB-Produkter $\mathrm{AB}$, Bromma Sweden), pH 4-7, and 5-7 (Biorad, Richmond, CA) in the proportion of $4: 1$ as described by Utermann et al..$^{10}$ Gels were polymerized in cylindrical tubes and run in a water-cooled column disc electrophoresis apparatus (Hoefer Scientific Instruments, San Francisco, CA) at $4^{\circ} \mathrm{C}$ for 16 hours at $150 \mathrm{~V}$. Samples of known phenotypes, E4:E3 and E2:E2 were included in each run. Gels were then removed from their tubes and stained with 1 to $2 \%$ aqueous Coomassie brilliant blue- $\mathrm{R}$ (Sigma Chemical Co., St-Louis, MO) using the method of Malik and Berrie. ${ }^{11}$

A typical electrophoresis banding pattern of apo $\mathrm{E}$ and apo $\mathrm{C}$ is illustrated in Figure 1. The various phenotypes were assigned according to the nomenclature as described by Zannis et al. ${ }^{2}$ The apo E phenotyping was done without prior knowledge of the clinical diagnosis as well as plasma lipid and lipoprotein values.

\section{Statistical analyses}

All values are expressed as mean \pm SEM. Comparisons between two groups were made by unpaired two-tailed Student's $\underline{t}$ test. Differences in frequency distribution of apo $E$ phenotypes were assessed by the $\mathrm{X}^{2}$-test.

\section{Results}

Plasma triglycerides were significantly increased by 29 percent $(p<0.01)$ in MyD as compared to the controls composed of spouses and first degree relatives (Table 1). When compared by age and sex with the lipid distribution values for American population reported by Rifkind and Segal, 12 MyD patients were situated near the 90th percentile for triglycerides, whereas the control group was in the 75 th percentile range. In contrast to triglycerides the plasma cholesterol concentration was not only 
similar in both MyD and controls but it was also in the normal 50th percentile reported by Rifkind and Segal. ${ }^{12}$ Despite similar concentration of cholesterol in both groups, the distribution of cholesterol in lipoprotein fractions was different as shown in Table 1. Corresponding to plasma triglyceride concentration, VLDL cholesterol was increased by 54 percent $(p<0.01)$ in MyD as compared to controls. On the other hand, LDL cholesterol was significantly lower by 9 percent $(P<0.05)$ in patients with MyD than controls. Furthermore, the LDL cholesterol level in the controls was similar to the mean value in the American population 12 whereas, LDL cholesterol level in patients with MyD was more near the 25th percentile. HDL cholesterol concentrations in both groups were similar and were also within the normal range of the reference values. ${ }^{12}$

As shown in Table 2, all six apo E phenotypes were represented in both groups, however, major differences were noticed in their frequency distribution in MyD patients and the controls. The most prevalent apo E phenotypes ${ }^{3}$ E3:E3 and E3:E2 showed the lowest frequency in $\mathrm{MyD}$ as compared to controls, whereas, phenotypes E4:E2 and E4:E3 showed the highest frequencies in $\mathrm{MyD}$, and these differences were significant. The rarer homozygous phenotype E2:E2 as reported in all population studies ${ }^{3}$ was equally distributed in both groups, and was also markedly more frequent as compared with other Caucasian populations. The E4:E4 homozygous phenotype was more common in MyD as compared to controls, but due to small numbers, these differences were not statistically significant.

Table 1: Plasma Lipid and Lipoprotein Concentrations $(\mathrm{mg} / \mathrm{dl})$ in Patients with MyD and Controls.

\begin{tabular}{lcc}
\hline \hline & Controls & MyD \\
\hline Number & 81 & 70 \\
Average Age (Years) & 39 & 36 \\
Cholesterol & $189 \pm 4$ & $191 \pm 6$ \\
HDL Cholesterol & $45.7 \pm 1.3$ & $48.2 \pm 1.4$ \\
LDL Cholesterol & $122.6 \pm 3.8$ & $111.3 \pm 4.4^{*}$ \\
VLDL Cholesterol & $21.0 \pm 1.3$ & $32.4 \pm 4.0^{* *}$ \\
Triglycerides & $168 \pm 9$ & $216 \pm 17^{* *}$ \\
\hline
\end{tabular}

${ }^{*} \mathrm{p}<0.05 ; \quad * * \mathrm{p}<0.01$.
Data on the concentrations of plasma lipids and lipoproteins in relation to various apo $E$ phenotypes are presented in Table 3. Since age and sex are both important determinants of plasma lipid and lipoprotein levels, each lipid and lipoprotein trait was adjusted for age and sex by linear regression. Only phenotypes with five or more subjects are shown for comparison.

In the controls, plasma cholesterol and LDL cholesterol concentrations showed a gradual reduction from the phenotype E3:E3 to E2:E2 in the order described. A similar trend was also seen for plasma triglycerides but not for VLDL cholesterol concentration. As compared to homozygous phenotype E3:E3, the heterozygous phenotype E4:E2 showed significantly higher concentrations of both plasma cholesterol and LDL cholesterol, but levels of VLDL cholesterol and triglycerides were not affected in the E4:E2 phenotype. In contrast the concentrations of all the traits in heterozygous E4:E3 phenotype were very similar to that in the homozygous E3:E3 phenotype.

In patients with $\mathrm{MyD}$ the plasma levels of triglycerides and VLDL cholesterol were significantly elevated in the phenotype E2:E2, whether compared to E3:E3 or corresponding E2:E2 in the controls. Similar trend was also noticed in patients with E4:E2 phenotype; plasma triglyceride levels were significantly higher, whether compared to E3:E3 or corresponding E4:E2 in the controls. The results on VLDL cholesterol were significant only when compared to E3:E3 in controls. Although similar trend was noticed in patients with E4:E3 phenotype, only the results on VLDL cholesterol were significantly different from

Table 2: Distribution of Apolipoprotein E Phenotypes in Patients with MyD and Controls

\begin{tabular}{lcc}
\hline APO E & & \\
Phenotype & Controls & MyD \\
\hline E2:2 & 8 & 10 \\
E3:2 & 24 & $4^{*}$ \\
E3:3 & 25 & $2^{*}$ \\
E4:2 & 5 & $13 \dagger$ \\
E4:3 & 17 & $35^{*}$ \\
E4:4 & 2 & 6 \\
\hline
\end{tabular}

${ }^{*} \mathrm{p}<0.001 ; \quad \dagger \mathrm{p}<0.02$

Table 3: Age and Sex Adjusted Levels (mg/dl) of Plasma Lipids and Lipoproteins in Relation to Apo E Phenotypes 1

\begin{tabular}{|c|c|c|c|c|c|}
\hline Phenotype (N) & C & LDL-C & VLDL-C & TG & $\underset{\text { ratio }}{\text { VLDL-C/TG }}$ \\
\hline \multicolumn{6}{|c|}{ CONTROLS } \\
\hline $\begin{array}{l}\text { E3:E2 (24) } \\
\text { E3:E3 (25) }\end{array}$ & $\begin{array}{l}183 \pm 6 \\
192 \pm 5\end{array}$ & $\begin{array}{l}111 \pm 7^{a} \\
125 \pm 4\end{array}$ & $\begin{array}{l}20.2 \pm 2.1 \\
21.8 \pm 2.3\end{array}$ & $\begin{array}{l}160 \pm 15 \\
178 \pm 15\end{array}$ & $\begin{array}{l}0.13 \pm 0.03 \\
0.12 \pm 0.02\end{array}$ \\
\hline E4:E2 (5) & $222 \pm 18^{a}$ & $156 \pm 13^{b}$ & $21.4 \pm 5.2$ & $163 \pm 27$ & $0.13 \pm 0.05$ \\
\hline E4:E3 (17) & $190 \pm 12$ & $125 \pm 10$ & $20.2 \pm 3.0$ & $171 \pm 22$ & $0.12 \pm 0.03$ \\
\hline E2:E2 (10) & $183 \pm 19$ & $76 \pm 6^{c^{*}}$ & $53.6 \pm 20.1^{b}$ & $242 \pm 60^{\mathrm{a}^{*}}$ & $0.22 \pm 0.06^{\mathrm{c} \dagger}$ \\
\hline E4:E2 (13) & $206 \pm 8$ & $117 \pm 8^{\dagger}$ & $39.8 \pm 8.7 b$ & $249 \pm 34^{a^{*}}$ & $0.16 \pm 0.04 \mathrm{a}^{*}$ \\
\hline E4:E3 (35) & $200 \pm 8$ & $127 \pm 6$ & $30.0 \pm 3.8^{*}$ & $228 \pm 25$ & $0.13 \pm 0.03$ \\
\hline $\mathrm{E} 4: \mathrm{E} 4(6)$ & $158 \pm 11^{\mathrm{c}}$ & $97 \pm 9 c$ & $12.3 \pm 1.0^{\mathrm{a}}$ & $101 \pm 12^{b}$ & $0.12 \pm 0.03$ \\
\hline
\end{tabular}

1 Data is not shown for the apo E phenotypes with $\mathrm{n}<5$

a, $p<0.05 ; b, p<0.01 ; c, p<0.001$; significance of the difference compared to apo E phenotype E3:E3 in the controls.

$*, 0.05<\mathrm{p}<0.10 ;+, \mathrm{p}<0.05$; significance of difference between corresponding phenotypes in the controls and MyD. 
E3:E3 phenotype. On the contrary, plasma concentrations of both triglycerides and VLDL cholesterol were significantly lower in patients with homozygous E4:E4 phenotype as compared to homozygous E3:E3 phenotype in controls.

The higher concentrations of triglycerides and VLDL cholesterol in MyD were accompanied by changes in the LDL cholesterol level in the phenotypes E2:E2, E4:E2 and E4:E4, but not in E4:E3. Thus, LDL cholesterol level was significantly lower in the E2:E2 phenotype in MyD as compared to E3:E3 as well as corresponding E2:E2 in the controls. The effects on LDL cholesterol and plasma cholesterol levels were manifested in the opposite direction in the E4:E4 phenotype in MyD, that is, their concentrations were significantly lower than in the E3:E3 phenotype.

\section{Discussion}

The genetic polymorphism of apo $\mathrm{E}$ is controlled by three alleles, $\varepsilon 2, \varepsilon 3$ and $\varepsilon 4$ at a single gene locus ${ }^{2}$ resulting in aminoacid substitutions in the three major isoproteins, E2, E3 and E4. These isoproteins determine the affinity of apo E-containing lipoproteins for lipoprotein receptors, ${ }^{4}$ thus E2 has lower affinity than E3 and E4. Another important aspect of apo E polymorphism is the variable effects of apo $E$ alleles on plasma lipid and lipoprotein concentrations. Thus $\varepsilon 2$ is associated with low and $\varepsilon 4$ with high plasma levels of cholesterol, LDL cholesterol and apo B. ${ }^{3}$ The metabolism of triglyceride-rich lipoproteins as well as apo $E$ itself is markedly influenced by the apo $E$ phenotypes. ${ }^{13,14}$ The present study demonstrates the variable effects of apo $\mathrm{E}$ phenotypes on plasma cholesterol, lipoprotein cholesterol and triglyceride levels in both affected and unaffected subjects from families with MyD.

As compared to controls, the plasma concentrations of triglycerides and VLDL cholesterol were elevated in MyD, whereas LDL cholesterol was decreased and HDL cholesterol was unaffected. Plasma cholesterol concentration was also unaffected due to concomitant increase and decrease in the concentrations of cholesterol in the VLDL and LDL fractions, respectively. Our results on hypertriglyceridemia in MyD are in concordance with the recent findings of Hudson et al ${ }^{15}$ who also reported that increased triglyceride and VLDL cholesterol concentrations were particular to $\mathrm{MyD}$ and were not associated with other forms of muscular dystrophies. Based on strong positive correlation between hypertriglyceridemia and hyperinsulinemia, these authors 15 concluded that increased VLDL levels in MyD were due to insulin resistance which is often part of a vicious cycle leading to hypertriglyceridemia. ${ }^{16}$ Indeed, hyperinsulinemia and generalized insulin resistance are among the most consistent features of $\mathrm{MyD}^{17}$ and furthermore, elevation of plasma VLDL is the most common alteration of lipoproteins in diabetic disorders. ${ }^{18}$ Our results also show that in MyD the concentration of plasma triglyceride was elevated to some extent in the various phenotypes E2:E2, E4:E2 and E4:E3, whereas it was decreased only in the phenotype E4:E4. Similar results were reported in type II diabetics, ${ }^{19}$ in whom plasma triglycerides were elevated in the various phenotypes E3:E2, E3:E3 and E4:E3, that were studied. Thus, elevated levels of plasma triglycerides in most of the apo $\mathrm{E}$ phenotypes in $\mathrm{MyD}$ is a common feature probably resulting from insulin resistance. On the other hand, the magnitude of increase in VLDL cholesterol may be influenced by the apo $E$ phenotypes as shown by our results in MyD. Thus, VLDL cholesterol concentration was increased by 33 and 79 percent respectively, in the phenotypes E4:E3 and $\mathrm{E} 2: \mathrm{E} 2$ as compared to E4:E3 in MyD. Also the ratio of VLDL cholesterol/plasma triglycerides was significantly higher in the phenotypes E2:E2 and E4:E2 ( 0.22 and 0.16 , respectively) in $\mathrm{MyD}$, as compared to ratios of 0.12 to 0.13 in all other phenotypes, both in controls and MyD. These results suggest the accumulation of intermediate density lipoprotein (IDL) particles ensuing hypertriglyceridemia, particularly in the E2:E2 phenotype in $\mathrm{MyD}$, but not in the corresponding phenotype in the controls. Similar results have been consistently reported in type III hyperlipoproteinemia, ${ }^{13}$ due to the poor recognition of apo E2 isoprotein by the hepatic cell receptors for apo E-containing lipoproteins. ${ }^{4}$

Our results on lower LDL cholesterol concentration in MyD are in contrast with lack of effect reported previously 15 in 10 patients. This discrepancy is reconcilable, taking into consideration that 7 of the 10 patients in the previous study had either E3:E3 or E4:E3 phenotypes and the other 3 had E3:E2 phenotype. Our results show that E3:E3 and E4:E3 phenotypes have no effect on LDL cholesterol concentration, since LDL cholesterol levels in both these phenotypes are similar to the mean LDL cholesterol level in the controls. Furthermore, LDL cholesterol levels in these phenotypes are similar in controls and $\mathrm{MyD}$, further illustrating the lack of effect of these phenotypes on the LDL cholesterol concentration. On the other hand, all other apo E phenotypes, E4:E2, E3:E2, E4:E4 and E2:E2 showed LDL cholesterol lowering effect to varying degree, from 6 to 39 percent in the order described, as compared to E3:E3 phenotype in controls. These phenotypes account for 33 of the 70 patients with MyD in our study, thus explaining lower concentration of LDL cholesterol.

The relation between apo $\mathrm{E}$ phenotypes and plasma LDL cholesterol levels has been documented previously, $3,13,20$ and there is general agreement that $\varepsilon 2$ increases and $\varepsilon 4$ decreases the concentration of LDL cholesterol as compared to $\varepsilon 3$ allele. Our results on lower LDL cholesterol in homozygous E2:E2 in both $\mathrm{MyD}$ and controls and intermediary levels in heterozygous E3:E2 phenotype in controls are in accordance with previous reports, and suggest that the clearance of LDL from the circulation is most likely higher in the E2 subjects, probably resulting from upregulated liver LDL (B, E) receptor activity. ${ }^{21}$ On the other hand, our results on apo E4 and plasma cholesterol are different from the previous studies. In the present study the association of E4 with E3 (heterozygous phenotype E4:E3) is without significant effect on plasma lipid and LDL cholesterol levels, while in the E4:E2 phenotype, both higher and lower concentrations of LDL cholesterol are noticed, suggesting interaction between the two isoproteins in relation to hypertriglyceridemia. Our data on the homozygous E4:E4 phenotype are of considerable interest. The simultaneous lowering of plasma levels of cholesterol, triglycerides, VLDL and LDL cholesterol suggest that the clearance of both VLDL and LDL particles is enhanced in the $\varepsilon 4$ homozygous subjects. These results are in agreement with lower plasma apo $\mathrm{E}$ concentration reported previously as well as increased clearance of radiolabelled E4 isoprotein in kinetic studies. ${ }^{14}$ The rapid metabolism of apo E4 may be due to its higher in vivo affinity for apo $E$ and/or LDL 
(B, E) receptors. These results are in contrast to the reported association between $\varepsilon 4$ and type $V$ hyperlipoproteinemia, 22 although the role of apo E4 in the accumulation of triglyceride rich lipoprotein particles remains to be established. It is likely that hypertriglyceridemia may be due to linkage of $\varepsilon 4$ allele with other genes such as apo C-I and apo C-II which are also located in the cluster ${ }^{23}$ apo E-C-I-C-II on the long arm of chromosome 19 and are involved in triglyceride metabolism.

\section{ACKNOWLEDGEMENT}

We would like to thank the laboratory staff of the lipid research unit for their skillful technical assistance and Ms Danielle Lemay and Doris Moreau for preparing the manuscript.

\section{REFERENCES}

1. Laberge C, Gaudet D, Morissette J, et al. Linkage of myotonic dystrophy and apo $\mathrm{E}$ in a French Canadian isolate. Cytogenet Cell Genet 1985; 81: 675-676.

2. Zannis VI, Breslow JL, Utermann G, et al. Proposed nomenclature of apo $\mathrm{E}$ isoproteins, apo $\mathrm{E}$ genotypes and phenotypes. J Lipid Res 1982; 23: 911-914.

3. Sing CE, Davignon J. Role of the apolipoprotein E polymorphism in determining normal plasma lipid and lipoprotein variation. Am J Hum Genet 1985; 37: 268-285.

4. Mahley RW, Innerarity TL. Lipoprotein receptors and cholesterol hemostasis. Biochim Biophys Acta 1983; 737: 197-222.

5. Wakamatsu $H$, Nakamura $H$, Ito $K$, et al. Concentration and fatty acid composition of serum lipids in myotonia dystrophica. Horm Metab Res 1972; 4: 458-462.

6. Poffenbarger PL, Pozefsky T, Soeldner JS. The direct relationship of proinsulin-insulin hypersecretion to basal serum levels of cholesterol and triglycerides in myotonic dystrophy. J Lab Clin Med 1976; 87: 384-396.

7. Moorjani S, Gagné C, Lupien P-J, et al. Plasma triglycerides related decrease in high density lipoprotein cholesterol and its association with myocardial infarction in heterozygous familial hypercholesterolemia. Metabolism 1986; 35: 311-316.

8. Mathieu J, Simard M, DeBrackeleer M, et al. Partial syndrome of myotonic dystrophy: clinical presentation and follow-up. Can J Neurol Sci, 1989; 16: 99-103.
9. Havel RJ, Eder HA, Bragdon HA. The distribution and chemical composition of ultracentrifugally separated lipoproteins in human serum. J Clin Invest 1955; 34: 1345-1353.

10. Utermann G, Hess M, Vogelberg KH. Broad-beta disease (hyperlipoproteinemia type III): Genetics, gene frequency and diagnosis without ultracentrifugation. In: Radola BJ, Graesslin D, eds. Electrofocusing and isotacophoresis. Berlin, Walter de Gruyter 1977; pp 281-293.

11. Malik N, Berrie A. New stain fixative for proteins separated by gel isoelectric focusing based on Commassie brilliant blue. Anal Biochem 1972; 49: 173-176.

12. Rifkind BM, Segal P. Lipid Research Clinics Program reference values for hyperlipidemia and hypolipidemia. J Amer Med Assoc 1983; 250: 1869-1872.

13. Utermann G, Kinderman I, Kaffarnik H, Steinmetz A. Apolipoprotein E phenotypes and hyperlipidemia. Hum Gent 1984; 65: 232-236.

14. Gregg RE, Zech LA Schaefer EJ, et al. Abnormal in vivo metabolism of apolipoprotein E4 in humans. J Clin Invest 1986; 78: 815-821.

15. Hudson AJ, Huff MW, Wright CG, et al. The role of insulin resistance in the pathogenesis of myotonic muscular dystrophy. Brain 1987; 110: 469-488.

16. Steiner $G$. Hypertriglyceridemia and carbohydrate intolerance: interrelations and therapeutic implications. Am J Cardiol 1986; 57: 27G-30G.

17. Harper PS. Myotonic dystrophy. Philadelphia: WB Saunders Co 1979.

18. Howard BV. Lipoprotein metabolism in diabetes mellitus. J Lipid Res 1987; 28: 613-628.

19. Eto M, Watanabe K, Iwashima Y, et al. Apolipoprotein E polymorphism and hyperlipemia in type II diabetics. Diabetes 1986; 35: 1374-1382.

20. Eto M, Watanabe K, Ischii K. Reciprocal effects of apolipoprotein $E$ alleles $(\varepsilon 2$ and $\varepsilon 4)$ on plasma lipid levels in normolipidemic subjects. Clin Genet 1986; 29: 477-484.

21. Weintraub MS, Eisenberg S, Breslow JL. Dietary fat clearance in normal subjects is regulated by genetic variation in apolipoprotein E. J Clin Invest 1987; 80: 1571-1577.

22. Ghiselli G, Schaefer EJ, Zech LA, et al. Increased prevalence of apolipoprotein E4 in type $\mathrm{V}$ hyperlipoproteinemia. J Clin Invest 1982; 70: 474-477.

23. Smit M, Kooij-Meijs EVD, Frants RR, et al. Apolipoprotein gene cluster on chromosome 19: Definite localization of apo C2 gene and the polymophic HpaI site associated with type III hyperlipoproteinemia. Human Genet 1988; 78: 90-93. 